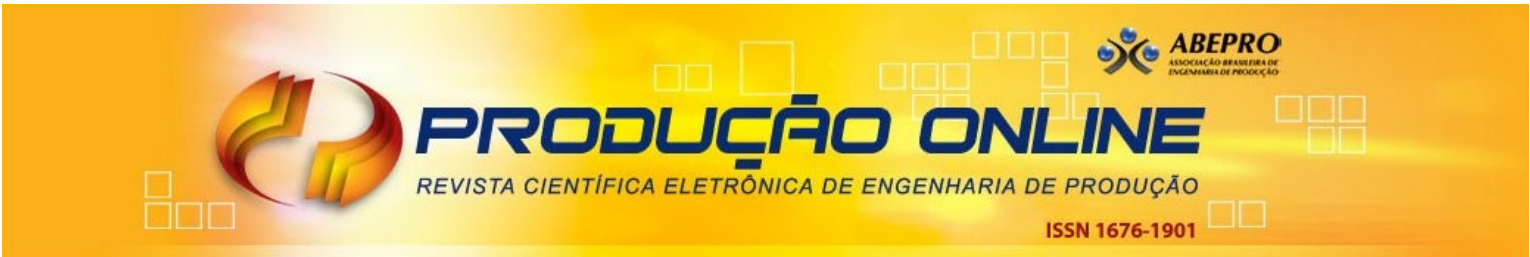

\title{
APLICAÇÃO E UTILIZAÇÃO DO MÉTODO UNIDADE DE ESFORÇO DE PRODUÇÃO (UEP) PARA ANÁLISE GERENCIAL E COMO FERRAMENTA PARA O AUMENTO DA COMPETITIVIDADE
}

\section{APPLICATION AND USAGE OF THE PRODUCTION UNIT EFFORT METHOD (UEP) FOR MANAGEMENT ANALYSIS AND AS COMPETITIVENESS SUPPORTING TOOL}

\author{
Peterson Diego Kunh*E-mail: petersonkunh@utfpr.edu.br \\ Antonio Carlos de Francisco* E-mail: acfrancisco@utfpr.edu.br \\ João Luiz Kovaleski* E-mail: kovaleski@utfpr.edu.br \\ *UTFPR - Universidade Tecnológica Federal do Paraná, Ponta Grossa - PR, Brasil,
}

\begin{abstract}
Resumo: O presente estudo demonstra como a utilização do método de custeio por unidade de esforço de produção (UEP), para calculo dos custos unitários de vários produtos produzidos por uma mesma indústria, pode ser utilizado como ferramenta para tomada de decisão e como diferencial competitivo para os gestores de produção, tendo em vista que as informações geradas detalham todos os custos que compõe o produto e seus respectivos gargalos que podem estar encarecendo o produto. $\mathrm{O}$ estudo do método foi realizado em uma empresa que atua no abate e processamento de carne de frango de corte, localizada no Paraná. Para realizar este estudo, foi desenvolvida uma pesquisa descritiva conclusiva, utilizando-se de dados primários e secundários. A metodologia apresenta ainda as muitas formas de se analisar o processo de industrialização e os produtos potenciais que geram mais lucratividade dentro do portfólio existente na empresa, maximizando dessa forma os resultados. Através do exemplo que será apresentado, poderão ser visualizados os custos unitários de cada produto e entender o roteiro deste produto com seus respectivos postos de trabalho e os esforços empregados em cada etapa da fabricação. Em poder das informações geradas pela metodologia de custeio por UEP o gestor poderá realizar uma analise comparando os produtos, seus esforços e identificando oportunidades de redução de custos possibilitando desta forma uma maior competitividade do seu produto final.
\end{abstract}

Palavras-chave: Produção. Decisão. Custo.

\begin{abstract}
The present study demonstrates like the use of the method pay for unity of effort of production, for calculation of the unit costs of several products produced by the same industry, can be used like tool for taking decision and like differential competitively for the manager of production, it tends in mind that the produced informations detail all the costs what it composes the product and his respective bottlenecks that can be raising the price of the product. The study of the method was carried out in an enterprise that acts in it slaughter and processing of meat of chicken, located in the Paraná. To carry out this study, was developed a descriptive concluding research, making use of primary and secondary data. The methodology presents still many forms of being analysed the process of industrialization and the potential products that produce more profitability inside the existent portfolio in the enterprise, maximizing in this form the results. Through the example that will be presented, will be able to be visualized the unit costs of each product and to understand the itinerary of this product with his respective posts of work and the efforts employed in each stage of the manufacture. In power of the informations produced by the methodology of funding for UEP the manager will be able to carry out an analysis comparing the products, his efforts and identifying
\end{abstract}

Revista Produção Online. Florianópolis, SC, v.11, n. 3, p. 688-706, jul./set., 2011. 
opportunities of reduction of costs making possible in this way a bigger competitiveness of his final product.

Key-words: Production. Decision. Cost.

\section{INTRODUÇÃO}

O mercado está continuamente se modificando e se tornando cada vez mais competitivo, com isso as empresas estão se capacitando e travando uma batalha continua em busca de clientes, não sendo mais seu tamanho um diferencial.

O presente estudo irá demonstrar a importância da utilização da metodologia de custeio por unidade de esforço de produção (UEP) no processo produtivo, bem como a importância da geração de informações gerenciais no processo de tomada de decisão, sendo um fator de sobrevivência para as empresas. Para facilitar a análise, a discussão será feita com base em um estudo de caso em uma indústria do Paraná que atua na atividade de abate e processamento de aves de corte, o foco do estudo é apresentar uma metodologia de custeio de produção que gere informação aos gestores para redução dos custos e como conseqüência tornando os produtos mais competitivos. Verifica-se que toda a indústria que produz mais de um item em seu portfólio tem dificuldades para calcular seus custos unitários e em função dessa dificuldade a escolha errada de uma metodologia de custo pode ser muito prejudicial.

A competitividade gerada pelo mercado global exige dos gestores informações precisas e rápidas, para que estes possam maximizar seus resultados e garantir a existência de suas empresas.

De acordo com Bornia (1995), dentre as varias tarefas da gerência de uma empresa, uma das principais é a detecção e eliminação das perdas ocorridas durante o processo, pois o mercado é muito dinâmico, exige a especialização e competência das atividades desenvolvidas pelas empresas.

A metodologia de UEP consiste em criar uma unidade de medida para os esforços empregados na fabricação dos produtos, possuindo uma referencia única onde todos os itens possam ser comparados.

Através da mensuração dos custos de produção por uma unidade padrão os gestores podem analisar todos os custos e tomar decisões sem que tenha um maior conhecimento da área de custos. 


\section{METODOLOGIA}

Este estudo teve natureza quantitativa e qualitativa em relação aos temas tratados. Aquele, durante a aquisição e o tratamento dos dados obtidos por meio de pesquisa de campo em um estudo de caso, cujo objeto de pesquisa foi uma indústria do Paraná que atua na atividade de abate e processamento de aves de corte, analisando um processo específico, onde foram realizadas entrevistas nãoestruturadas aos profissionais da área e observação participante.

Já o qualitativo, durante a interpretação dos dados, realizando um elo com a realidade verificada, durante a análise e aplicação do método de custeio por Unidade de Esforço de Produção obtidos na bibliografia relevante da área, sendo a base primordial no desenvolvimento deste estudo (RICHARDSON, 1999).

O método de custeio é apresentado no capítulo 4 deste trabalho através de sua utilização em uma indústria de alimentos na análise do mix de produção de um corte de ave, com o auxilio do gráfico de Pareto pode-se verificar o produto de maior participação, para posteriormente detalhar seus custos, podendo ser gerado informações de margem de contribuição de cada produto que auxiliam no processo de tomada de decisão.

\section{GESTÃO ESTRATÉGICA DE CUSTOS}

É importante considerar que num ambiente de grande concorrência a escolha da metodologia de custos e sistema de informações gerenciais deve ser relevante, pois a eficácia na busca pelo lucro só é possível para quem possuir uma visão sistêmica do processo, para que possam identificar o mix ideal de vendas com produtos de maior valor agregado e consiga atuar sobre os produtos que geram menos lucro tornando-os mais competitivos.

O gerenciamento de custos deve ser considerado de importância vital ao sucesso nos negócios de uma empresa (FAGUNDES, 2009).

Atualmente a revolução tecnológica repercute diretamente nos resultados das empresas, sobre a forma que as empresas demonstram suas informações e 
principalmente na velocidade das tomadas de decisões, de tal maneira que quem não manter um sistema eficaz está muito longe de conseguir resultados positivos em suas negociações.

Toscani (1998), diz que o controle de custos organiza, analisa e interpreta os custos dos produtos, dos inventários, dos serviços, dos componentes da organização, dos planos operacionais e das atividades de distribuição para determinar o lucro.

O gerenciamento de custos exige um conjunto de procedimentos empregado para a determinação do custo de um produto e das várias atividades relacionadas para sua fabricação e venda, para auxiliar o planejamento e a mensuração de desempenho da empresa.

Os custos diretos ou indiretos permitem informações suficientes para chegar ao valor real do custo de produção de cada produto. Dutra (1995, p. 35), define "custo direto é aquele que pode ser diretamente apropriado a cada tipo de bem ou órgão, no momento da sua ocorrência, isto é, está ligado diretamente a cada tipo de bem ou função."

Portanto, custos diretos são todos os custos que possuem facilidade na sua percepção, sendo diretamente relacionados ao produto feito.

Crepaldi (1999, p. 59), acrescenta que "os custos indiretos são os custos que dependem de cálculos, rateios ou estimativas para serem apropriados em diferentes produtos, portanto, que só são apropriados indiretamente aos produtos".

O termo indireto, significa ser impossível uma segura identificação de seus valores e quantidades em relação ao produto.

De acordo com Martins (1998, p. 56), "os custos fixos são os que num período tem seu montante fixado não em função de oscilações na atividade: Variáveis os que têm seu valor determinado em função da oscilação na produção."

Portanto, custos fixos são aqueles cujo total não varia proporcionalmente ao volume produzido, como por exemplo, o aluguel e o seguro, já os custos variáveis variam proporcionalmente ao volume produzido, ou seja, se não houver quantidade produzida, o custo variável será nulo. Exemplos de custos variáveis: matéria-prima e embalagens. 
Conforme Martins (1998, p. 25), conceitua custo como "o gasto relativo à bem ou serviço utilizado na produção de outros bens ou serviços. E despesas como os bens ou serviços consumidos direta ou indiretamente para a obtenção de receita."

Quando uma organização não conhece seus respectivos potenciais de gerar lucro através da redução dos custos unitários na fabricação ou na escolha da melhor programação de produção reduzindo gargalos produtivos ou ainda antes de investir em um processo produtivo a empresa não analisa onde o dinheiro pode gerar mais resultado ela deixa de ganhar ou gerar lucro, traduzindo-se em um custo de oportunidade.

Martins (1998), define os custos de oportunidade, como sendo: o valor do beneficio que se deixa de ganhar quando, no processo decisório, se toma um caminho ou uma alternativa em detrimento de outra.

Entre os custos de oportunidade que existem no processo produtivo existem ainda as perdas que por sua vez devem ser consideradas como custo de oportunidade, ou seja, o lucro que a empresa deixou de realizar por ter perdido.

A perda é considerada por Martins (1998, p. 26), como "um bem ou serviço consumido de forma anormal e involuntária, não sendo um sacrifício feito com intenção de obtenção de receita, sendo exemplos mais comuns: perda com incêndios e obsoletismo de estoques".

Sob estas proposições, a gestão de custos e sistemas de custeio estão estreitamente vinculados à trajetória estratégica escolhida pela empresa. Esta trajetória terá influência decisiva na definição e desenvolvimento do sistema de custos a ser implantado na indústria.

\subsection{Contabilidades de Custos}

A contabilidade de custos consiste em um ramo da contabilidade, propriamente dita, cujo objeto de estudo é o custeio de um produto ou serviço.

Para Martins (1998), o objetivo da contabilidade de custos é, portanto, identificar, mensurar e registrar transações econômicas realizadas por uma entidade que impactem diretamente no valor a ser atribuído a um produto ou serviço produzido ou executado pela mesma. 
O objetivo da contabilidade de custo é fornecer informações sobre os produtos, de tal forma que essas informações possam auxiliar a administração da empresa na tomadas de decisões.

Nos dias atuais a contabilidade de custos informa dados para que a empresa realize previsões, avaliações, planejamento, controle e fixações de preço, uma vez que para competir no mercado é preciso buscar a maximização dos lucros.

Para Leone (2000), uma das vantagens da contabilidade de custos é que ela pode e deve fornecer informações de custos diferentes para atender necessidades gerenciais diferentes.

A contabilidade de custos requer assim, a existência de métodos de custeio para que, ao final do processo, seja possível obter-se o valor a ser atribuído ao objeto de estudo. Os principais métodos de custeio são: custeio por absorção; custeio variável; custeio por atividade; custeio $\mathrm{ABC}$, e o custeio por UEP.

\subsection{O Método Unidades de Produção (UP)}

O método de unidades de produção é muito útil para indústrias que possuem em sua linha de produção diferentes produtos sendo fabricados, pode ser uma ferramenta muito útil para os gestores, pois segundo Allora (1995, p. 8), o método UP significa "tecnologia de gestão de desempenho e custos voltada para a melhoria de processos, redução de custos dos produtos, aumento da rentabilidade dos produtos e melhoria real da lucratividade da empresa".

Para Morozini (2006, p. 146), uma das vantagens deste método é que ele "permite medir o desempenho da produção, verificar a viabilidade de aquisição de novos equipamentos, programador de produção e comparar processos, entre outros."

A produção de uma fábrica durante um determinado período corresponde ao conjunto de objetos fabricados, sejam acabados, semi-acabados ou em andamento (ALLORA, 1996).

As quantidades e tipos de artigos fabricados em uma indústria são enumerados para medir o desempenho realizado em determinado período, considerando-se que o número de peças, os metros na tecelagem e confecções, o 
quilograma na fundição e mecânica, as horas de trabalho, são todas unidades imperfeitas, que não refletem o verdadeiro valor e desempenho da produção (ALLORA, 1995). Portanto a produção não dispõe de uma unidade de medida própria, quaisquer que sejam os produtos fabricados.

De acordo com Bornia (1995), uma das vantagens da utilização deste método é devido a simplificação na maneira de realizar os cálculos de produção de um período, devido a utilização de uma única unidade me medida para todos os produtos da empresa.

Segundo explica Allora (1995, p. 52), as medidas comumente usadas na indústria são unidades imperfeitas, porque "não representam o verdadeiro valor da produção." Concluem os autores que através destas medições não existe uma unidade de medida que permita medir com exatidão uma produção, qualquer que sejam os produtos fabricados.

O método UP, vem para resolver este problema, pois representa uma unidade única para medir a produção diversificada de uma empresa, obtendo-se uma melhor idéia de produção e evitando-se que as quantidades e tipos de artigos fabricados sejam simplesmente enumerados.

\subsection{Utilizações do Método UP}

$\mathrm{Na}$ explicação sobre o Método UP, até aqui verificada, percebe-se sua importância de forma generalista. Contudo, Allora (1995), alerta que este método deve ser adaptado a cada tipo de fábrica, pois durante sua implantação são verificadas necessidades específicas.

Pois de acordo com Külzer (2008), por meio de uma única unidade de medida é possível medir qualquer produção, por mais diversificada que seja. Assim, chegase ao preço dos produtos pelo conhecimento das despesas totais necessárias para a fabricação.

Segundo Allora (1996, p. 57), "para cada posto operativo - PO calculam-se os custos valores dos seus esforços de produção unitários e assim fixam-se estes esforços em custo-valor/hora, denominados de "foto-índice do posto operativo" ou somente "FIPO", todos estes em um determinado instante no tempo." 
Para Bornia (1995, p. 4) "posto operativo é um conjunto de operações, podendo ser diferente de um posto de trabalho ou máquina."

O calculo do foto-índice é uma das etapas mais importantes, pois é nela que são determinados os custos horários dos postos operativos. De acordo com Morozini (2006, p. 147) "os índices são calculados tecnicamente de acordo com o efetivo dispêndio de insumos por parte dos postos operativos em funcionamento, sem agregar o valor da matéria-prima e das despesas com estrutura."

O autor Allora (1996, p. 57 e 58), comenta que os principais itens de custo de transformação (esforço) considerados para o cálculo dos FIPO são os seguintes:

a) Mão de Obra direta: Valor do salário de registro em carteira, isto é, salário puro sem repouso remunerado, mas contendo os adicionais de periculosidade, insalubridade e noturno;

b) Supervisão e Mestria: Supervisores, mestres, encarregados, etc., atribuídos às operações conforme o grau de atenção despendido durante o processo de fabricação;

c) Encargos Sociais: São todos os encargos sociais de lei que a empresa é responsável a pagar para cada unidade monetária de salário pago, mais os benefícios concedidos pela empresa para cada funcionário;

d) Depreciações Técnicas: As regras fiscais determinam que uma máquina ou equipamento deva ser depreciado conforme regras pré-estabelecidas, sendo também seu valor calculado através do patrimônio. Para o perfeito estabelecimento entre as relações dos esforços dos PO's não podemos utilizar conceitos como estes, devemos calcular então as amortizações técnicas baseadas em valores reais dos equipamentos e suas vidas úteis verdadeiras;

e) Material de Consumo Específico: São os materiais de consumo da própria máquina, ou seja, os materiais que a máquina consome durante a sua operação para poder executar suas tarefas;

f) Peças de Manutenção: São as peças de manutenção gastas nos equipamentos;

g) Energia Elétrica: Calculado de acordo com o consumo do equipamento em KW;

h) Manutenção: É o valor gasto pelo departamento de manutenção atribuído aos PO's de acordo com as horas consumidas deste departamento;

i) Utilidades: São todos os gastos dos equipamentos que não transformam as matérias-primas, mas ajudam os PO's a transformá-la. Por exemplo: Compressores, ponte rolante, equipamentos de geração de frio, caldeiras, que serão atribuídos somente aos postos que a consomem e não ao setor.

Durante o processo após definir os PO's e os itens de despesas que pertencem a estes PO's, deve-se realizar uma coleta de dados necessários para o cálculo dos FIPO's. Depois de realizado esta coleta, os mesmos serão tratados, possibilitando desta forma a realização do cálculo dos FIPO's dos vários PO's.

Os "FIPO's se constituem da somatória de todos os custos dos diversos itens, alocados para cada posto operativo" (ALLORA, 1996, p. 59). 
Seguindo a lógica desta metodologia deve-se agora calcular o foto-índice de base - "FIPB", que, conforme Allora (1995) corresponde ao custo realizado para fabricar uma unidade do produto de base em um momento determinado, levando em consideração as despesas utilizadas na formação dos FIPO.

Para poder realizar este cálculo, deve ser selecionado o produto que é mais representativo para a empresa, o gráfico de Pareto pode ser uma ferramenta muito útil para esta visualização, o qual será chamado de produto base, pode ser o produto que passa pelo maior número de PO's. O produto base será o responsável pela absorção das variações nos itens de despesas alocados aos FIPO, tornando constantes as UP's dos produtos em função das variações que poderão ocorrer nestes itens de despesas ao longo da utilização do método. "O foto-índice de base é obtido através da somatória, cujas parcelas são obtidas pela multiplicação do fotoíndice dos PO's pelos tempo em que o produto base é trabalhado nestes postos" (ALLORA, 1996, p. 59).

O valor de uma UP corresponde a um múltiplo do índice base, que por sua vez, corresponde ao valor monetário deste produto para as condições de funcionamento idealizado, no instante considerado (ALLORA, 1996).

Em seguida obtém-se as UP/h dos PO's. Isto será feito dividindo-se os fotoíndice (FIPO) de cada PO, pelo foto-índice de base (FIPB), gerando a UP/h de cada posto operativo.

"O valor em UP's de um produto ou peça é calculado através de um somatório que corresponde à multiplicação das UP/h dos POs pelos respectivos tempos que o produto ou peça considerado permanece nestes postos" (ALLORA, 1996, p. 60).

Assim, são verificadas as UP's dos produtos, que representam a transformação da matéria-prima em produto acabado. A obtenção do custo de transformação de cada produto faz-se pela contagem de quanto à empresa produziu em um determinado período. Esta contagem é obtida pela multiplicação dos valores em UP's de cada produto pelas quantidades produzidas de cada um, chegando assim a uma produção total da empresa expressa em UP's (ALLORA, 1996).

Para a informação do total de gastos de produção, excluem-se as matérias primas utilizadas em determinado período e suas embalagens, ou seja, os custos de 
produção podem ser calculados pelo UP em determinado período, dividindo-se o total dos gastos de produção pelo total das UP's produzidas obtendo-se o valor monetário para cada UP produzida durante este período (ALLORA, 1995).

Por ultimo deve-se calcular o custo de transformação de cada produto, através da multiplicação do seu valor em UP's pelo valor monetário de uma unidade de produção do período analisado, obtendo-se como resultando o seu custo de transformação (ALLORA, 1996).

\section{RESULTADOS E DISCUSSÕES}

Quando uma empresa tem informações detalhadas de seus gastos e consegue quantificar os esforços destinados a produção de cada um de seus itens, como propõe a metodologia de custeio por UP, é possível rastrear o roteiro operacional de cada produto em seus respectivos postos de trabalho e identificar quais postos agregam valor e os que não agregam valor. Exemplo disso é a atividade desossar um peito de ave em um frigorífico produzindo um filé de peito, atividade que para o consumidor agrega valor, em contra partida as atividades que não agregam valor são aquelas que são necessárias durante o processo para que o produto possa ser modificado, mas não são percebidas pelo consumidor final, como por exemplo o transporte de uma seção para outra.

Através do mapeamento dos postos de trabalho é possível identificar gargalos produtivos e perdas como: atividade desnecessária, má utilização da capacidade, movimentos e métodos desnecessários. Que podem ser complementado pelas medidas de produtividade que são consideradas ferramentas importantes utilizadas no gerenciamento de custos que permitem localizar pontualmente em que fatores da produção há problemas de desempenho (FAGUNDES, 2009).

Para facilitar a identificação das oportunidades é necessária a utilização de algumas ferramentas da qualidade como, por exemplo, o gráfico de Pareto.

De acordo com Oliveira (2006, p.40), através do diagrama de Pareto "é possível a visualização das causas de um problema evidenciando o que possui uma maior freqüência/gravidade identificando-se o motivo que iniciou o problema". Sendo uma ferramenta utilizada para estabelecer uma ordem ou priorização das causas de 
problemas. No embasamento teórico foi evidenciado que a metodologia de UP consiste em transformar o esforço empregado em uma unidade de medida, transformado os gastos de reais por hora em UP's por hora, em cada atividade.

$\mathrm{Na}$ implementação da metodologia é necessário qualificar cada atividade por meio de uma classificação de agregação de valor, antes da escolha do foto-índice. De acordo com Morozini (2006, p. 147), o foto-índice "representa o custo por hora atividade de todos os itens necessários para o perfeito funcionamento do processo técnico capaz de transformar a matéria-prima em produto acabado". No entanto é necessário que todo o foto-índice sejam contabilizados na mesma unidade de capacidade, e se referindo a um mesmo período.

Na seqüência é necessário separar as atividades que podem ser classificadas como custos fixos e as atividades que podem ser classificadas como custos variáveis. Cada produto deve conter um roteiro por onde ele irá passar durante sua transformação com uma descrição detalhada de todos os gastos com mão de obra direta/indireta, encargos sociais e todos os gastos diretos. Deve-se classificar as atividades em: atividade homem, atividade máquina, atividade transporte, atividade de verificação e checagem, entre outras. A classificação objetiva quantificar as oportunidades de redução do custo de produção do item.

Durante a implementação da metodologia se faz necessário uma série de estudos de cada atividade e suas devidas classificações, o objetivo dessas classificações é identificar, à medida que cada produto é produzido, qual atividade demanda mais esforço e se as atividades agregam ou não valor ao produto final.

É possível demonstrar a eficácia da metodologia por meio de um exemplo fictício de uma indústria de alimentos, como se segue abaixo na Tabela 1 , onde é apresentado um mix de produtos com suas respectivas quantidades produzidas:

Tabela 1 - Analise do mix de produção de um corte de ave - sasami 


\begin{tabular}{lccc}
\hline Produto & $\begin{array}{c}\text { Qtde produzida } \\
\text { (mês) }\end{array}$ & $\begin{array}{c}\text { Acumulado } \\
\text { (Kg/mês) }\end{array}$ & Participação \\
\hline Sasami IQF & 390.000 & 390.000 & $63,12 \%$ \\
Sasami 6x2 & 140.000 & 530.000 & $85,78 \%$ \\
Sasami blc & 40.880 & 570.880 & $92,39 \%$ \\
Sasami pct & 32.000 & 602.880 & $97,57 \%$ \\
Sasami bdj & 15.000 & 617.880 & $100,00 \%$ \\
\hline
\end{tabular}

Nesta fase, utilizando-se o gráfico de Pareto conforme Gráfico 1, o gestor pode fazer uma primeira analise escolhendo o produto de maior participação e detalhar seus custos.

Gráfico 1 - Analise de produção sasami utilizando o gráfico de Pareto

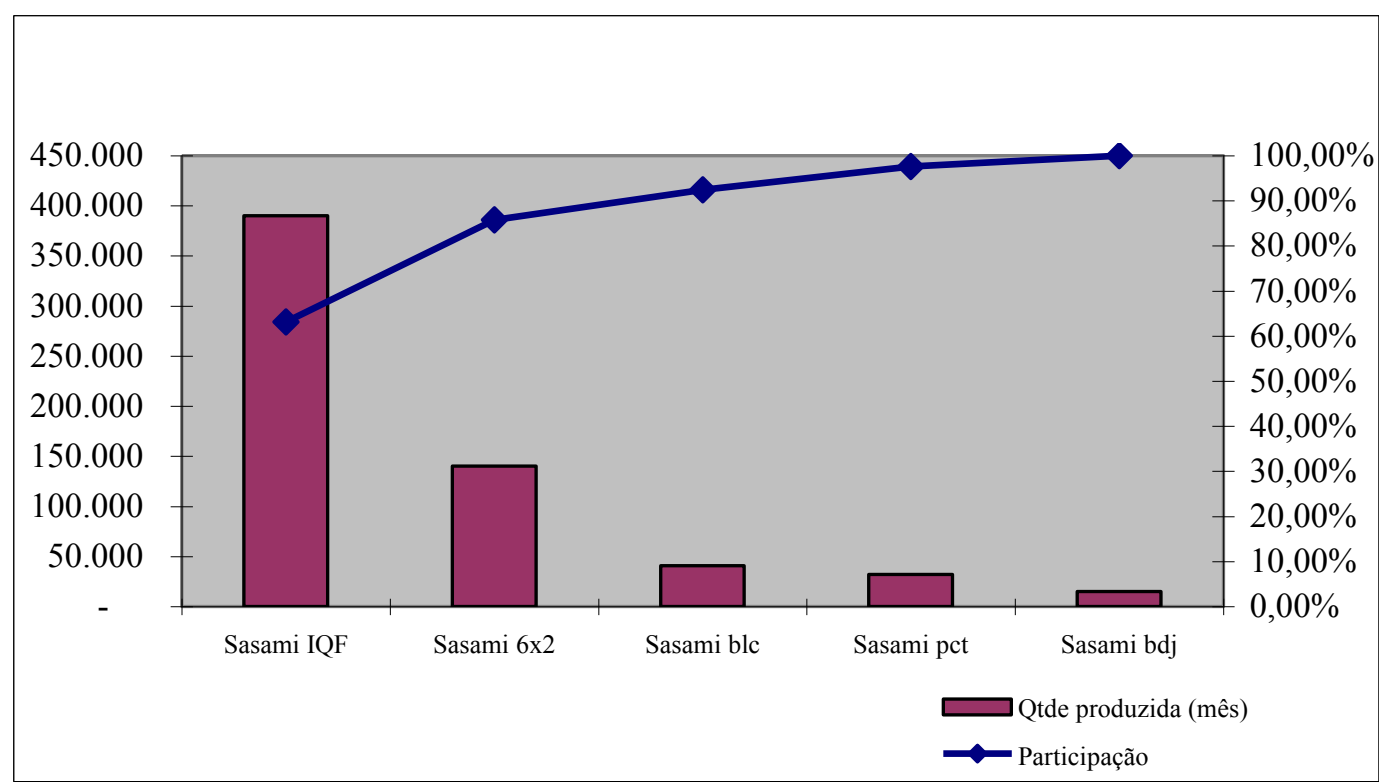

O exemplo citado, corte de ave - sasami é uma matéria prima proveniente da desossa do peito de frango, a partir do corte, a indústria pode dar vários destinos a essa matéria prima transformando esse insumo em " $\mathrm{n}$ " produtos finais.

O sasami de frango é um músculo integro com as características semelhantes ao filé de peito de frango.

Como se pode observar a utilização do gráfico de Pareto quando associado ao método UP's torna-se uma ferramenta de analise poderosa, consegue-se focalizar onde ocorrem os maiores esforços de produção no processo de fabricação dos produtos, postos operativos que necessitam de maiores esforços, bem como custos envolvidos, analisados por linhas de produção, células, mini-fábricas, enfim, 
da maneira que a situação demandar, ampliando, deste modo, o potencial de retorno (OLIVEIRA, 2006).

Na segunda etapa é necessário destacar o produto de maior participação no mercado, a partir dessa informação, é possível através do detalhamento do roteiro de produção deste item identificar todas as fases de fabricação do item e o nível de esforço aplicado pela geração de UP, o detalhamento do roteiro gera informações, como a produtividade hora em cada posto de trabalho, custos fixos e variáveis em função do esforço empreendido na fabricação, se atividade agrega ou não valor para o produto acabado, etc.

Como se pode observar durante a atividade de produção do produto de maior participação, sasami IQF, realizou-se a classificação dos postos operativos, como na empresa analisa já foram classificados e numerados, utilizou-se a numeração e classificação conforme Tabela 2 abaixo:

Tabela 2 - detalhamento do produto de maior participação de mercado do exemplo anterior

\begin{tabular}{|c|c|c|c|c|c|}
\hline $\begin{array}{l}N^{0} \\
\text { PO }\end{array}$ & Postos Operativos & $\begin{array}{l}\text { Esforço } \\
\text { UP }\end{array}$ & Acumulado & $\begin{array}{c}\text { \% em } \\
\text { relação } \\
\text { ao total }\end{array}$ & $\begin{array}{c}\% \% \\
\begin{array}{c}\text { Acumula } \\
\text { do }\end{array}\end{array}$ \\
\hline 20 & Cortar ponta do sasami & 25 & 25 & $30 \%$ & $30 \%$ \\
\hline 35 & Congelar sasami IQF & 17 & 42 & $20 \%$ & $50 \%$ \\
\hline 65 & Congelar sasami & 9 & 51 & $11 \%$ & $61 \%$ \\
\hline 40 & Embalar sasami & 8 & 59 & $10 \%$ & $70 \%$ \\
\hline 45 & Pesar sasami & 6 & 65 & $7 \%$ & $77 \%$ \\
\hline 70 & Paletizar sasami & 4 & 69 & $5 \%$ & $82 \%$ \\
\hline 50 & Selar pacote de sasami & 3 & 72 & $4 \%$ & $86 \%$ \\
\hline 60 & Encaixotar sasami & 3 & 75 & $4 \%$ & $89 \%$ \\
\hline 10 & Riscar sasami & 2 & 77 & $2 \%$ & $92 \%$ \\
\hline 15 & Extrair sasami & 2 & 79 & $2 \%$ & $94 \%$ \\
\hline 30 & $\begin{array}{l}\text { Transportar para congelamento } \\
\text { IQF }\end{array}$ & 2 & 81 & $2 \%$ & $96 \%$ \\
\hline 55 & $\begin{array}{l}\text { Transportar sasami } \\
\text { embalagem secundária }\end{array}$ & 2 & 83 & $2 \%$ & $99 \%$ \\
\hline 25 & $\begin{array}{l}\text { Transportar sasami } \\
\text { embalagem }\end{array}$ & 1 & 84 & $1 \%$ & $100 \%$ \\
\hline
\end{tabular}

No exemplo ficou evidenciado que o posto que exige mais esforço é o posto operativo (PO) n $n^{\circ} 20$, conforme Gráfico 2 que representa o custo de produção por posto operativo, que é um posto que executa a operação de retirada do tendão de ligamento do sasami, executado por colaboradores com facas ou tesouras. 
Gráfico 2 - Custo de produção por posto operativo sasami utilizando o gráfico de Paretto

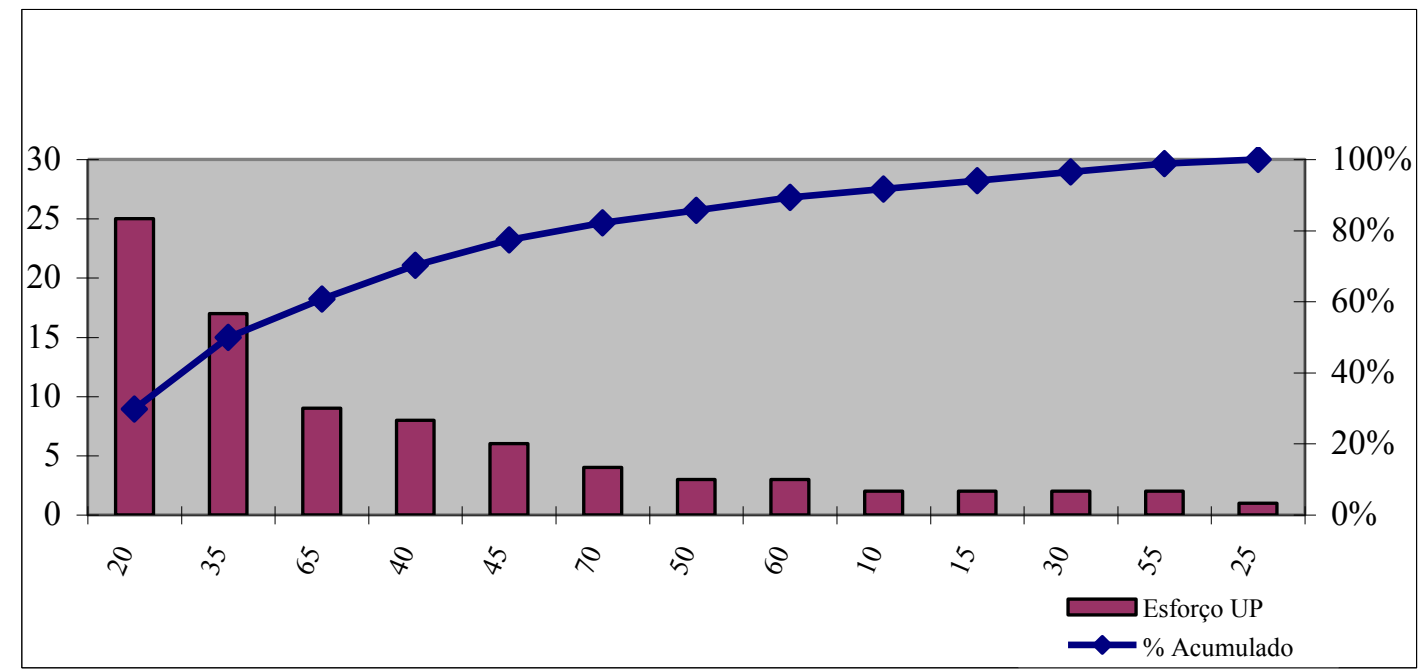

A retirada do tendão é um beneficiamento do produto sasami, alguns clientes exigem esse recorte como requisito de qualidade do produto final, o processo de retirada é manual e o funcionário corta com uma tesoura ou uma faca a ponta do tendão, melhorando o aspecto visual do produto.

Numa terceira etapa é possível que o gestor identifique por que o posto operativo (PO) $n^{\circ} 20$ é o posto de trabalho que exige maior esforço estratificando seus componentes, podendo identificar quais componentes exige um maior esforço, conforme Tabela 3:

Tabela 3 - Identificação do posto operativo que exige maior esforço

\begin{tabular}{lcccc}
\hline Tipo de custo & Gasto R\$/h & $\begin{array}{c}\text { Acumulad } \\
\mathbf{0}\end{array}$ & $\begin{array}{c}\text { \% em } \\
\text { relação ao } \\
\text { total }\end{array}$ & $\begin{array}{c}\text { \% } \\
\text { Acumulad } \\
\text { o }\end{array}$ \\
\hline MOD & $\mathrm{R} \$ 12,00$ & 12 & $35 \%$ & $35 \%$ \\
Encargos Sociais & $\mathrm{R} \$ 8,00$ & 20 & $24 \%$ & $59 \%$ \\
Materiais de consumo & $\mathrm{R} \$ 4,00$ & 24 & $12 \%$ & $71 \%$ \\
MOI & $\mathrm{R} \$ 3,00$ & 27 & $9 \%$ & $79 \%$ \\
Amortização técnica & $\mathrm{R} \$ 2,00$ & 29 & $6 \%$ & $85 \%$ \\
Manutenção & $\mathrm{R} \$ 2,00$ & 31 & $6 \%$ & $91 \%$ \\
Peças de manutenção & $\mathrm{R} \$ 1,00$ & 32 & $3 \%$ & $94 \%$ \\
Energia elétrica & $\mathrm{R} \$ 1,00$ & 33 & $3 \%$ & $97 \%$ \\
Utilidades & $\mathrm{R} \$ 1,00$ & 34 & $3 \%$ & $100 \%$ \\
\hline
\end{tabular}

Detalhado os componentes do posto operativo é fácil identificar que o maior gasto está relacionado à conta mão-de-obra direta (MOD), que pode ser melhor 
visualizado através do Gráfico 3, tendo em vista que é uma atividade manual. A partir destas informações é possível, por exemplo, iniciar um estudo de automação desta atividade para identificar se existe viabilidade financeira no projeto, ou ainda estudar novos métodos que possam aumentar a produtividade do posto operativo.

Gráfico 3 - Composição do custo de produção do produto sasami utilizando o gráfico de Pareto

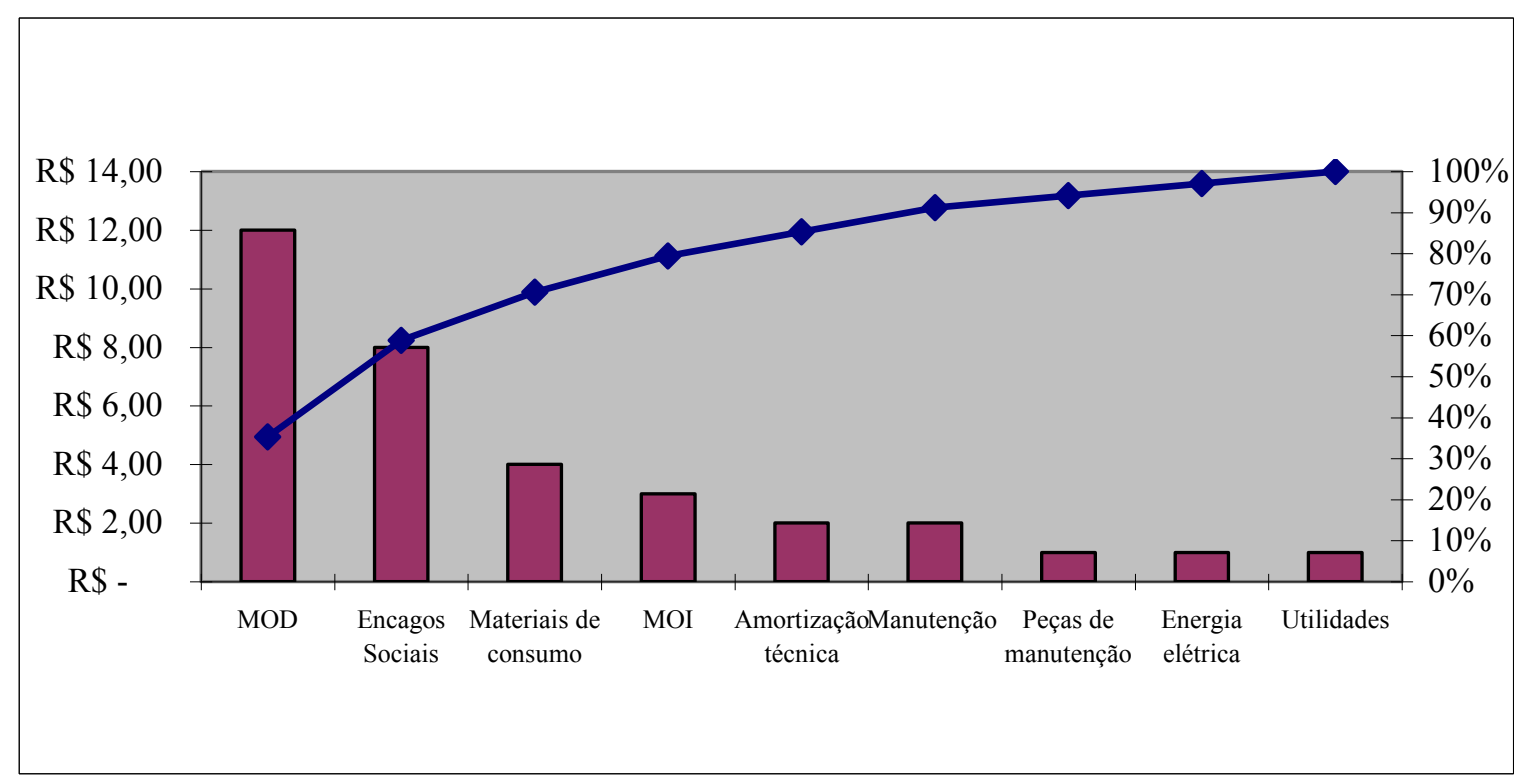

A partir do conhecimento detalhado dos custos fixos e variáveis pelo método UP e dos conceitos relacionados ao método, torna-se possível gerar informações de margem de contribuição para os produtos, Tabela 4, depois é claro de esgotadas as alternativas para se reduzir os custos de produção, com os dados gerados a partir da margem de contribuição o gestor consegue visualizar qual produto contribui melhor para o pagamento de seus custos fixos.

Tabela 4 - Margem de contribuição por produto

\begin{tabular}{lccc}
\hline Produto & Receita (R\$/t) & $\begin{array}{c}\text { Custos } \\
\text { variáveis (R\$/t) }\end{array}$ & $\begin{array}{c}\text { Margem de } \\
\text { contribuição } \\
\text { (R\$/t) }\end{array}$ \\
\hline Sasami IQF & 5.220 & 4.050 & 1.170 \\
Sasami bdj & 5.050 & 3.820 & 1.230 \\
Sasami pct & 4.850 & 3.730 & 1.120 \\
Sasami 6x2 & 4.756 & 3.175 & 1.581 \\
Sasami blc & 4.600 & 3.520 & 1.080 \\
\hline
\end{tabular}


De acordo com o Gráfico 4, fica evidenciado na análise que o produto com maior participação nas vendas não é o produto que mais contribui para pagamento dos custos fixos.

\section{Gráfico 4 - Margem de contribuição por produto}

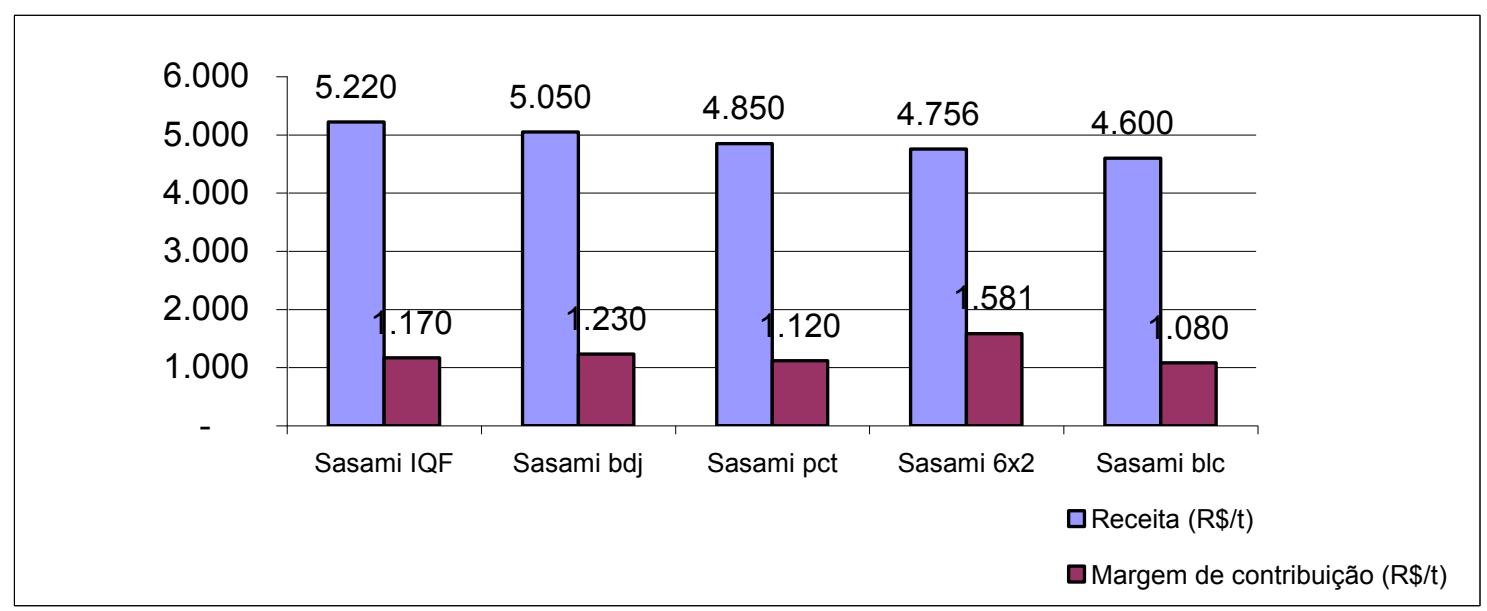

Para produtos com as mesmas matérias primas e com embalagens semelhantes e que fazem parte de uma mesma família de itens é possível por meio das informações geradas compor sugestões de novas ordens de produção com o máximo de resultado possível.

A grande vantagem do método de custeio por UP se dá ao fato do gestor ter grande clareza e precisão de quais produtos pode gerar mais rentabilidade e quais geram, mesmo que a empresa possua em seu portfólio milhares de produtos. Depois de identificado qual produto tem menor potencial de ganho e geração de resultado, pode-se desenvolver trabalhos de melhorias com foco em melhorias do resultado como foi exemplificado anteriormente

Durante a coleta de dados é necessário que o analista identifique a capacidade real de produção de cada produto, tendo em vista, que o sistema apropria os custos em função da capacidade produtiva de cada posto de trabalho. Tendo como memória de cálculo essas informações o sistema de UP's gera informações de utilização da capacidade ociosa da fábrica e identifica o potencial de redução de custos com o aumento da produção instalada da fábrica. 
Gerando informações sobre a capacidade ociosa o gestor pode atuar sobre os custos de oportunidade alterando o mix de produção quando necessário ofertando novos volumes ao departamento comercial.

A metodologia é de fácil entendimento tendo em vista que a mesma não gera informações contábeis e financeiras, os produtos são valorizados em UP e a produção é mensurada em unidades de produção padrão, por exemplo, se uma fábrica produz sasami de ave ou coração de ave o operador receberá a informação de quantas UP's cada item custa, e ainda é possível saber se um determinado posto de trabalho foi eficiente na geração de UP's durante o exercício.

\section{CONCLUSÕES}

A metodologia de analise apresentada é uma ferramenta poderosa onde o gestor poderá utilizar as informações geradas para analise de seu processo produtivo, evidenciando onde poderá estar alocando esforços que irão melhorar o desempenho de sua atividade.

Através da aplicação do método em uma indústria de alimentos durante a análise do mix de produção de um corte de ave, com o auxilio do gráfico de Pareto, pode-se identificar qual produto possui uma maior participação levando em consideração a quantidade produzida, para posteriormente detalhar seus custos verificando o roteiro de produção deste item e todas as suas fases de fabricação, produzindo informações sobre os níveis de esforço aplicado pela geração de UP's.

No exemplo ficou evidenciado que o posto que exige mais esforço é o posto operativo numero 20 , o qual teve seus componentes estratificados identificando-se claramente que o maior gasto esta relacionado a mão-de-obra direta.

De posse destas informações é possível estudar novos métodos de trabalho que possam aumentar a produtividade do posto operativo ou mesmo realizar um estudo de automação desta atividade.

Verifica-se que a metodologia de unidade de esforço de produção é bastante útil principalmente quando temos em uma indústria vários produtos sendo fabricados, facilitando assim o calculo dos custos unitários, devendo ser utilizada como ferramenta para tomada de decisão e como diferencial competitivo para os 
gestores de produção, tendo em vista que as informações geradas detalham todos os custos que compõe o produto e seus respectivos gargalos que podem estar encarecendo o produto final.

O estudo do método foi realizado em uma empresa que atua no abate e processamento de carne de frango de corte, mas também poderia ser aplicado a outros processos produtivos que possuem características semelhantes e um grande mix de produtos.

Através dos indicadores proporcionados pela metodologia, pode-se analisar o processo de industrialização e os produtos potenciais que geram mais lucratividade, maximizando dessa forma os resultados e como conseqüência pode-se entender melhor o roteiro dos produtos com seus respectivos postos de trabalho e os esforços empregados em cada etapa da fabricação, identificando principalmente oportunidades de redução de custos.

\section{REFERÊNCIAS}

ALLORA, F.; ALLORA, V. UP' - Unidade de medida da produção. São Paulo: Pioneira, 1995.

ALLORA, V.; GANTZEL. Revolução nos custos. Salvador: Casa da Qualidade Ltda., 1996.

BORNIA, A. C. A utilização do método da unidade de esforço de produção na quantificação das perdas internas da empresa. CONGRESSO INTERNACIONAL DE CUSTOS, 4, 1995, Campinas, UNICAMP. Anais...Campinas 1995. v. 1. p. 493-505.

CREPALDI, S. A. Contabilidade gerencial: teoria e prática. São Paulo: Atlas, 1999.

DUTRA, R. G. Custos: uma abordagem prática. 4 ed. São Paulo: Atlas, 1995.

FAGUNDES, A. B.; VAZ, C. R.; HATAKEYAMA, K. A relação entre os custos e receitas ambientais como principal indicador do desempenho econômicoambiental das organizações. Revista Produção-Online, v.9, n. 3, 2009.

KÜLZER, L. A.; LIMA, J. D. de; ADAMCZUK, G.; TRENTIN, M. G.; PESSA, S. L. R. Implementação de sistemas de custos - estudo de caso em indústria metalúrgica de pequeno porte. ENEGEP, 28, 2008, Rio de Janeiro. Anais...Rio de Janeiro, 2008.

LEONE, G. S. G. Curso de contabilidade de custos. 2. ed. São Paulo: Atlas, 2000. 
MARTINS, E. Contabilidade de custos. 6 ed. São Paulo: Atlas, 1998.

MOROZINI, J. F.; GASS, C. T.; CARPENEDO, C. L.; ZUFFO, C. R. R. Aplicação da abordagem UEP em uma empresa do setor fabril: um estudo de caso. Revista Sistemas \& Gestão, v. 1, n. 2, p. 142-155, maio/ago. 2006.

OLIVEIRA, S. E.; ALLORA, V; SAKAMOTO, F. T. C. Utilização conjunta do método UP' (Unidade de Produção -UEP') com o diagrama de pareto para identificar as oportunidades de melhoria dos processos de fabricação: um estudo na agroindústria de abate de frango. Revista Custos e @gronegócio on line, v.2, n.2, jul./dez., 2006.

RICHARDSON, R. Jarry. Pesquisa social, métodos e técnicas. 3. ed. São Paulo: Atlas, 1999.

TOSCANI, A. Apostila de análise de custos. São Paulo: Melhoria da Qualidade, 1998.

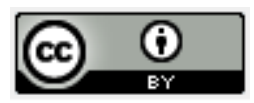

Artigo recebido em 24/04/2010 e aceito para publicação em 17/08/2011. 